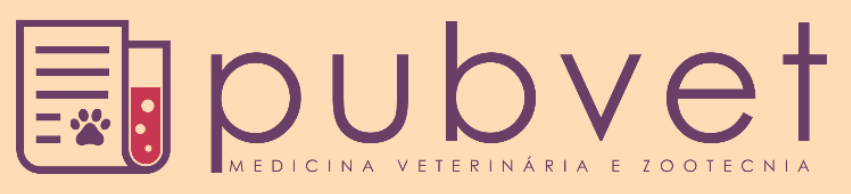

https://doi.org/10.31533/pubvet.v12n10a191.1-9

\title{
Doenças transmitidas por alimentos e principais agentes bacterianos envolvidos em surtos no Brasil: revisão
}

\author{
Eveny Silva de Melo ${ }^{1^{*}}{ }^{\bullet}$, Wenderson Rodrigues de Amorim ${ }^{1} \bullet$, Raizza Eveline Escórcio \\ Pinheiro $^{2}{ }^{\bullet}$, Paulo Gomes do Nascimento Corrêa ${ }^{3}$, Sávio Matheus Reis de Carvalho ${ }^{4}{ }^{\bullet}$, \\ Alan Rodrigo Sousa Soares $\operatorname{Santos}^{3}{ }^{\bullet}$, Danielle de Souza Barros ${ }^{1} \bullet$, Elke Taline Alencar \\ Cavalcante Oliveira ${ }^{5}{ }^{\circ}$, Carine Augusto Mendes $^{6}$, Flávio Vieira de Sousa ${ }^{7} \bullet$

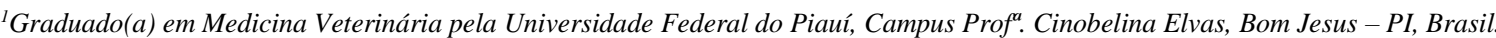 \\ ${ }^{2}$ Docente da Universidade Federal do Piauí, Departamento de Medicina Veterinária, Campus Ministro Petrônio Portella, Teresina-PI, Brasil. \\ ${ }^{3}$ Discente de Medicina Veterinária, Universidade Federal do Piauí, Campus Profa. Cinobelina Elvas, Bom Jesus - PI, Brasil. \\ ${ }^{4}$ Residente em Medicina Veterinária pela Universidade Federal do Piauí, Campus Ministro Petrônio Portella, Teresina - PI, Brasil. \\ ${ }^{5}$ Mestranda em Saúde da Mulher pela Universidade Federal do Piauí, Campus Ministro Petrônio Portella, Teresina - PI \\ ${ }^{6}$ Discente de Ciências Biológicas pela Universidade Federal do Piauí, Campus Profa. Cinobelina Elvas, Bom Jesus - PI \\ ${ }^{7}$ Mestrando em Produção Animal pela Universidade Federal do Piauí, Campus Profa. Cinobelina Elvas, Bom Jesus - PI \\ *Autor para correspondência, E-mail: evenymelo06@hotmail.com
}

RESUMO. As Doenças Transmitidas por Alimentos (DTA) são síndromes constituídas de anorexia, náuseas, vômitos e/ou diarreia, acompanhadas ou não de febre, porém não se limitam a sintomas digestivos, podendo ocorrer manifestações extraintestinais. São atribuídas à ingestão de alimentos ou água contaminados, podendo ser causadas por agentes físicos, químicos ou biológicos, sendo este último grupo representado pelos parasitas, vírus e, em especial, as bactérias, que podem atuar diretamente sob o organismo do indivíduo ou através da produção de toxinas. A ocorrência de DTA é um grave problema em saúde pública, uma vez que estas apresentam um impacto significativamente negativo tanto no contexto social, em decorrência das vítimas que sofrem seus agravos, quanto no econômico, onde grandes perdas são geradas nos ramos da indústria, comércio e turismo. Apesar disso, para muitas pessoas este é um assunto tratado de forma irrelevante ou até mesmo para alguns ainda desconhecido, o que se torna um agravante deste problema. $\mathrm{O}$ objetivo deste estudo é fazer uma revisão apresentando o panorama das DTA no Brasil, os aspectos gerais relacionados a estas doenças e as principais bactérias envolvidas em surtos no país.

Palavras chave: alimentos contaminados, bactérias, saúde pública, sintomas digestivos, toxinas

\section{Foodborne diseases and major bacterial agents involved in outbreaks in Brazil: review}

ABSTRACT. Foodborne Diseases (DTA) are syndromes consisting of anorexia, nausea,
vomiting and / or diarrhea, with or without fever, however these are not limited to digestive
symptoms, and extraintestinal manifestations may occur. Are attributed to the ingestion of
contaminated food or water and may be caused by physical, chemical or biological agents,
the latter group being represented by the parasites, viruses and in particular the bacteria,
which may act directly under the organism of the individual or through production of
toxins. The occurrence of DTA is a serious problem in public health, since these have a
significant negative impact both in the social context, due to the victims that suffer their
aggravations, as in the economic one, where large losses are generated in the branches of 
industry, commerce and tourism. Despite this, for many people this is a matter treated irrelevantly or even for some still unknown, which becomes an aggravating of this problem. The objective of this study is to make a review presenting the panorama of DTA in Brazil, the general aspects related to these diseases and the main bacteria involved in outbreaks in the country.

Keywords: contaminated food, bacteria, public health, digestive symptoms, toxins

\title{
Enfermedades transmitidas por alimentos y principales agentes bacterianos involucrados en brotes en Brasil: revisión
}

\begin{abstract}
RESUMEN. Las Enfermedades Transmitidas por Alimentos (DTA) son síndromes que consisten de anorexia, náuseas, vómitos y / o diarrea, acompañadas o no de fiebre, pero no se limitan a los síntomas digestivos, pudiendo acontecer manifestaciones extraintestinales. Se atribuyen a la ingesta de alimentos o agua contaminados, pudiendo ser causados por agentes físicos, químicos o biológicos, siendo este último grupo representado por los parásitos, virus y, en especial, las bacterias, que pueden actuar directamente en el organismo del individuo o a través de la producción de toxinas. La incidencia de DTA es un grave problema en salud pública, ya que éstas presentan un impacto significativamente negativo tanto en el contexto social, como consecuencia de las víctimas que sufren sus agravios, como en el económico, donde grandes pérdidas se generan en el ramo de la industria, comercio y turismo. Sin embargo, para muchas personas este es un tema tratado de forma irrelevante o incluso para algunos todavía desconocido, lo que se vuelve un agravante de este problema. El objetivo de este estudio fue hacer una revisión presentando el panorama de las DTA en Brasil, los aspectos generales relacionados a estas enfermedades y las principales bacterias involucradas en brotes en el país.
\end{abstract}

Palabras clave: alimentos contaminados, bacterias, salud pública, síntomas digestivos, toxinas

\section{Introdução}

A alimentação e a nutrição constituem requisitos básicos para a proteção e promoção da saúde, possibilitando assim um potencial de qualidade de vida para cada indivíduo (Marchi et al, 2011). Entretanto, os alimentos podem sofrer contaminações ao longo das etapas de elaboração, possibilitando assim o desenvolvimento de enfermidades de origem alimentar (Flores \& Melo, 2015).

As síndromes, resultantes da ingestão de alimentos contaminados são conhecidas como Doenças Transmitidas por Alimentos (DTA). Existem aproximadamente 250 tipos de doenças alimentares, responsáveis por sérios problemas de saúde pública e expressivas perdas econômicas (Oliveira et al., 2010). Sua principal característica é o desenvolvimento de sinais e sintomas entéricos que acometem a população, em geral podendo resultar em surtos de variadas proporções (Dias et al., 2011).

Dentre os diferentes agentes causadores de DTA estão os microrganismos patogênicos e suas toxinas, agentes químicos, físicos ou biológicos (Marinho et al, 2015). Entretanto, o primeiro grupo é o mais significativo, onde encontram-se uma ampla variedade gêneros e espécies com diferentes patogenias, períodos de incubação e duração de sintomas (Forsythe, 2013).

A segurança alimentar é, de fato, importante para a manutenção da saúde pública, no entanto, apesar de práticas e sistemas de monitoramento avançados instalados em vários países, casos de DTA ou surtos continuam a ser comuns, persistindo como um grave problema (Tharuk et al, 2010).

Diante desse contexto, esta revisão objetiva apresentar o panorama nacional das DTA, seus aspectos gerais, além de relacionar as principais bactérias envolvidas em surtos de doenças desta categoria no Brasil, revelando o quão importante este tema é para o bem e conservação da saúde coletiva.

\section{Panorama nacional das DTA}

No mundo contemporâneo as doenças transmitidas por alimentos apresentam grande 
incidência. Cada vez mais os alimentos sofrem processos de manipulação e industrialização, isso possibilita maiores chances de contaminação e crescimento de patógenos (Machado, 2013).

A economia dos países sofre consequências em decorrência dos crescentes índices de DTA através da perda de renda dos indivíduos afetados, cuidados médicos à população, perda de produtividade, custos com investigações à surtos, perda de renda em razão do fechamento de negócios e perdas no comércio quando os consumidores evitam comprar produtos envolvidos em surtos (Forsythe, 2013).

Diversos fatores estão envolvidos na emergência das DTA como a existência de grupos populacionais vulneráveis ou mais expostos, urbanização desordenada, produção de alimentos em grande escala, deficiências no controle da qualidade dos alimentos, maior contato da população com "fast-foods", consumo de alimentos em vias públicas, aumento no uso de aditivos, mudanças ambientais, globalização e a facilidade de deslocamento da população (BRASIL, 2004).

Em decorrência da fragilidade dos programas de controle existentes ou da ausência de sistemas de vigilância sanitária, as informações existentes a respeito das DTA não representam a real magnitude do problema. Em alguns países o número real de DTA tem uma frequência 300 a 350 vezes maior do que indicam os relatos oficiais (Silva, 2009).

No Brasil, mesmo com criação do Sistema Nacional de Vigilância Epidemiológica das Doenças Transmitidas por Alimentos (VE-DTA), implantado em 1999 para reduzir a incidência e subsidiar medidas de prevenção e controle para as DTA (Malacrida et al., 2017) o desempenho entre os estados ainda é heterogêneo, havendo até os que nunca identificaram surtos (Luna \& Silva Júnior, 2013).

Entre os anos 2000 a 2017 foram notificados 12.503 surtos de DTA no Brasil, destes apenas 3.196 foram confirmados laboratorialmente, sendo a identificação do agente etiológico obtida apenas em 2.593 , onde $92,2 \%$ foram de origem bacteriana (BRASIL, 2018).

De acordo com dados do Sistema de Informação de Agravos de Notificação (SINAN), nos últimos 17 anos as regiões Sudeste e Sul apresentaram os maiores índices de DTA no Brasil, com percentuais de $39,2 \%$ e $33,9 \%$, respectivamente, aparecendo o Nordeste em terceiro lugar, com 15,5\% (BRASIL, 2018). Entretanto, acredita-se que as maiores incidências ocorrem no Nordeste, em decorrência dos casos não diagnosticados e/ou subnotificados (Guilherme \& Esteves, 2017).

\section{Aspectos gerais das DTA}

De acordo com a Organização Mundial da Saúde (OMS) as doenças transmitidas por alimentos são aquelas de natureza infecciosa ou tóxica causadas pela ingestão de alimentos ou água contaminados por agentes biológicos, químicos e físicos, representando um sério risco à saúde (BRASIl, 2010).

As DTA podem originar surtos, episódios onde duas ou mais pessoas apresentam sinais ou sintomas semelhantes, em um mesmo período de tempo, após a ingestão de um alimento da mesma origem, com confirmação por evidência clínica, epidemiológica e/ou laboratorial (Marchi et al., 2011).

A ingestão de alimentos sem alterações sensoriais é apontada como uma das principais causas de surtos, uma vez que estes não são associados com alimentos fonte de DTA, diferente daqueles com aparência ou odor desagradáveis, que normalmente são rejeitados pelos consumidores (Marinho et al., 2015).

$\mathrm{O}$ contato das mãos do manipulador com o alimento é muito importante na sua contaminação (Oliveira, 2010). A preparação com antecedência ou em quantidades excessivas, exposição prolongada à temperatura ambiente e descongelamento inadequado, influenciam na proliferação dos agentes. Já o aquecimento, cocção ou reaquecimento insuficientes, contribuem para a sobrevivência dos patógenos (Sirtoli \& Camarella, 2018).

Em relação aos principais locais de ocorrência de surtos, em ordem de importância estão, as residências, seguidas de restaurantes, instituições de ensino, refeitórios, festas, unidades de saúde e ambulantes (Ferraz et al., 2015). A maioria dos eventos ocorrem em domicílios devido a falhas higiênicas na manipulação e contaminação cruzada através de utensílios ou ambientes contaminados (Nunes et al., 2017).

Crianças, idosos, imunocomprometidos e gestantes estão dentro do grupo de risco para as DTA, podendo ser acometidos com mais facilidade e desenvolverem complicações mais 
sérias se não tratados adequadamente e em tempo hábil (

Devido aos hábitos culturais de alimentação e à necessidade de optar por produtos com menor preço, os quais geralmente apresentam qualidade inferior e contaminações, as camadas menos favorecidas da população em geral são apontadas como as mais acometidas pelas afecções alimentares (Welker et al., 2010).

Alguns fatores de risco influenciam a susceptibilidade do indivíduo no desenvolvimento de uma DTA. Em relação aos patógenos, tem-se a dose ingerida e a virulência; quanto ao hospedeiro, a idade, estado imunológico, higiene pessoal e susceptibilidade genética; já a dieta tem importância em casos de deficiências nutricionais, ingestão de gorduras ou alimentos tamponados (Forsythe, 2013).

Durante todas as etapas de elaboração e até mesmo após o seu término os alimentos podem sofrer contaminações (Flores \& Melo, 2015). Dentre os principais alimentos envolvidos em surtos estão os ovos e produtos que os utilizem como base, água, doces e sobremesas, leite e derivados, carnes de aves, suínos e bovinos in natura, cereais, hortaliças e pescados (BRASIL, 2016).

Os ovos em geral são estéreis internamente, entretanto, material fecal da ave, gaiola ou ninho, além da água utilizada na lavagem, manipulação e a embalagem, podem contaminar sua superfície externa. Já os produtos cárneos, durante as etapas do abate, processamento e estocagem facilmente podem ser contaminados, além disso, apresentam condições favoráveis à proliferação de microrganismos, como variedade de nutrientes, umidade e baixa acidez. (Klein et al., 2017).

A contaminação dos alimentos pode acontecer através de perigos químicos e físicos ou de agentes biológicos (Silva et al., 2010). Exemplos de contaminantes de natureza química são metais pesados, agrotóxicos, antibióticos e toxinas de animais ou plantas, os físicos podem ser pedaços de vidro ou fragmentos metálicos e a contaminação de natureza biológica, considerada a mais importante para a saúde pública, é atribuída às bactérias, vírus, fungos e parasitas (BRASIL, 2010).

A manifestação de uma DTA pode ocorrer em uma das seguintes formas. Toxinfecção, resulta da ingestão de alimentos contaminados com microrganismos patogênicos que produzem ou liberam toxinas após ingeridos (Malacrida et al., 2017). Infecção, decorrente da ingestão e posterior multiplicação do patógeno no intestino (Germano \& Germano, 2015), com invasão da mucosa ou penetração de tecidos (Teixeira, 2010). Intoxicação, causada pela ingestão de toxinas microbianas produzidas durante sua proliferação nos alimentos (Pizzolito et al., 2007).

O período de incubação de uma DTA depende do agente etiológico envolvido, podendo variar de horas à meses (BRASIL, 2010). Em geral, a maioria dos casos se resolve em 24 a 48 horas, sem necessidade de intervenção médica. Em decorrência disso grande parte das DTA não é diagnosticada e os surtos não são notificados (Amson et al., 2006).

As DTA podem se apresentar desde ligeiras indisposições à situações que requerem cuidados hospitalares ou mesmo culminarem em morte (Marchi et al., 2011). Dentre os principais sintomas estão náuseas, vômitos e diarreias, acompanhadas ou não de febre (BRASIL, 2010).

Entretanto, sintomas digestivos não são as únicas manifestações. Meninges, rins, fígado, sistema nervoso central, terminações nervosas periféricas, dentre outros, também podem ser afetados, a depender do agente envolvido (Malacrida et al., 2017).

\section{Principias bactérias envolvidas em surtos de DTA no Brasil}

As bactérias constituem um grupo microbiano de alta incidência que apresenta ampla diversidade e virulência, o que lhes confere grande importância frente à sua capacidade de provocar danos à saúde humana (Silva et al., 2017).

De acordo com o tipo de manifestação clínica as bactérias causadoras DTA podem ser divididas em grupos. As infecciosas mais importantes são Salmonella, Campylobacter e E. coli, as principais intoxicantes são Bacillus cereus, Staphylococcus aureus e Clostridium botulinum e no grupo das toxigênicas $E$. coli enterotoxigênica, Vibrio cholerae, Vibrio parahaemolyticus, Clostridium perfringens e Bacillus cerus são exemplos clássicos (BRASIL, 2010).

Nos últimos 17 anos os principais agentes envolvidos em surtos de DTA no Brasil foram Salmonella spp., Escherichia coli e Staphylococcus aureus (BRASIL, 2018). 


\section{Salmonella}

As salmonelas são bactérias em formato de bacilo, gram-negativas, não encapsuladas, anaeróbias facultativas e que não esporulam. O gênero Salmonella é o mais importante da família Enterobacteriaceae, sendo composto pelas espécies Salmonella bongori e Salmonella entérica, subdividida em seis subespécies (Cardoso \& Tessari, 2013), sendo em cada uma reconhecidos diferentes números de sorovares (BRASIL, 2011).

As infecções causadas pelas bactérias deste gênero são consideradas as mais importantes causas de DTA e costumam apresentar três classificações: a febre tifoide, causada pela Salmonella Typhi, as febres entéricas causadas por $S$. Paratyphi (A, B, C) e as enterocolites ou salmoneloses, causadas pelas demais salmonelas (Cardoso \& Carvalho, 2006).

A salmonelose pode acometer apenas um indivíduo ou apresentar-se em surtos (BRASIL, 2011). A principal forma de transmissão ocorre pela via fecla-oral, através da ingestão de água ou alimentos contaminados podendo também acontecer por contato direto com animais infectados (Gabaron et al., 2015).

A maioria dos casos de salmonelose ocorre pela ingestão de alimentos preparados e armazenados inadequadamente, o que contribui para a multiplicação do agente e aumento da dose ingerida (Morrow \& Funk, 2001). Os principais alimentos envolvidos são carnes bovina, suína e de aves, ovos e leite (Cangen, 2011).

Normalmente a dose infectante varia entre $10^{5}$ e $10^{8}$ células, entretanto, em pacientes imunocomprometidos, doses inferiores a $10^{3}$ já foram observadas para alguns sorovares envolvidos em surtos. No Brasil, os principais sorovares identificados foram $S$. Enteritidis, com maior ocorrência, seguido de $S$. Typhi e $S$. Paratyphi (BRASIL, 2011).

Os sintomas da salmonelose em geral surgem entre 12 a 72 horas após exposição ao agente e incluem febre, dor abdominal, diarreia, náusea e vômito, podendo durar por até 7 dias (Morrow \& Funk, 2001). Porém, sorovares mais virulentos como $S$. Thyphi podem estender a infecção por até oito semanas, causando septicemia e levando à morte (BRASIL, 2011).

Embora os quadros entéricos sejam mais comuns, manifestações extraintestinais como infecções septicêmicas, osteomielite, artrite, hepatite podem acontecer (BRASIL, 2011). Além disso, após a infecção alguns indivíduos passam à condição de portadores assintomáticos, por meses ou anos, tornando-se uma fonte de infecção (Shinohara et al., 2008).

\section{Escherichia coli}

A Escherichia coli (E. coli) é uma espécie de bactérias pertencente à família Enterobacteriaceae. São bastonetes gramnegativos, não esporulados, móveis ou não e anaeróbios facultativos (Pinto, 1996)

Esta espécie foi considerada como um habitante comensal da microbiota entérica de mamíferos e aves durante muito tempo. Entretanto, após o reconhecimento de diversas patologias entéricas e extraintestinais causadas por diversos sorotipos de $E$. coli esta visão mudou (Berchieri Júnior et al., 2015), passando a ser apontada como um dos agentes bacterianos mais frequentes em DTA (Macedo et al., 2018).

As estirpes patogênicas de E. coli são resultantes de clones que adquiriram atributos de virulência específicos, isto lhes confere capacidade de adaptação à outros nichos e potencial para provocar um amplo espectro de doenças (Karper et al, 2004). As amostras patogênicas de E. coli são classificadas de acordo com seus mecanismos de virulência (Mittelstaedt \& Carvalho, 2006).

A E. coli enterotoxigênica (ETEC) é responsável por causar a chamada diarreia dos viajantes. Esta bactéria se fixa à mucosa intestinal e produz toxinas, resultando em uma diarreia aquosa. A sintomatologia inclui febre baixa, cólicas abdominais, náuseas e fadiga, com duração entre 3 a 19 dias (Cangen, 2011).

A cepa enteropatogênica (EPEC) causa diarreia aquosa em crianças e bebês. Os principais sintomas observados são vômitos, febre e diarreia aquosa com muco. A $E$. coli enteropatogênica coloniza as microvilosidades intestinais e produz lesões características de ligação ou desaparecimento das bordas (FIB, 2011), não produzindo toxinas nem causando doença invasiva (Madigan et al., 2016).

A E. coli enterohemorrágica (EHEC) pode causar diarreia sanguinolenta, colite hemorrágica, síndrome urêmica hemolítica e púrpura trombótica trombocitopênica (FIB, 2011). As amostras desta $E$. coli também são conhecidas como STEC, produtora de toxina Shiga-like ou 
VTEC, produtora de toxina Verotoxina, sendo esses termos referentes à mesma toxina (Mittelstaedt \& Carvalho, 2006).

As cepas de E. coli enteroinvasiva (EIEC) colonizam o cólon (FIB, 2011). Quando são fagocitadas por enterócitos se multiplicam e invadem outras células desse tipo, levando à sua morte. Dentre os principais sintomas estão arrepios, febre, fezes com sangue, dores abdominais e de cabeça (Lan et al., 2004).

A transmissão das infecções causadas por $E$. coli pode se dar através do contato direto com animais ou humanos acometidos ou ainda por meio do consumo de alimentos contaminados (Caldorin et al., 2013). Os principais alimentos envolvidos em contaminações são carne, salsicha, leite cru, queijo, alface, melão, rabanete e água (Gyles, 2007).

A detecção de bactérias desta espécie em alimentos é um dado muito importante, uma vez que sua presença além de indicativa de contaminação fecal ainda pode compreender cepas patogênicas que possibilitarão o desenvolvimento de casos ou surtos de DTA (Caldorin et al., 2013).

\section{Staphylococcus aureus}

As bactérias da espécie Staphylococcus aureus (S. aureus) pertencem à família Micrococcaceae, são cocos gram-positivos e anaeróbios facultativos, mas que têm maior crescimento sob condições aeróbias, quando produzem catalase (Lopes et al., 2006).

Os $S$. aureus são comumente encontrados na pele e cavidades nasais de humanos. Sua presença no organismo de um indivíduo normalmente não provoca lesões aparentes, entretanto sob algumas condições estes microrganismos podem se tornar patogênicos, causando uma ampla variedade de infecções (Sales \& Silva, 2012).

A intoxicação alimentar por estafilococos é uma DTA comum, resultante da ingestão de toxinas pré-formadas, produto da multiplicação bacteriana em alimentos deixados em uma faixa de $36^{\circ} \mathrm{C}$, ideal ao crescimento deste microrganismo (Feitosa et al., 2017). Embora muitas espécies do gênero sejam associadas a surtos, $S$. aureus é a mais frequentemente identificada, frente à sua alta capacidade de produção de enterotoxinas (Omoe, 2005).

Alimentos manipulados por portadores do patógeno em secreções nasofaríngeas ou com ferimentos nas mãos, abcessos ou acnes, produtos de origem animal mal cozidos ou refrigerados inadequadamente e superfícies ou equipamentos contaminados estão entre os modos de transmissão e contaminação por este patógeno (Barreto, 2010).

Os principais alimentos contaminados são carnes de bovinos, frangos e peixes, principalmente fatiadas, produtos lácteos como leite, queijos e coalhadas, molhos para saladas, cogumelos, enlatados, presento, salame, produtos de panificação e cremes de ovos (Forsythe, 2011).

Para que a toxina seja acumulada em quantidade suficiente para provocar uma intoxicação a dose infectante de $S$. aureus apresenta-se próxima de $10^{6}$ células por grama de alimento ingerido (Rodrigues et al., 2004).

Quadros de intoxicação estafilocócica apresentam um período incubação variando entre 15 minutos a 8 horas, sendo em média de 2 a 4 horas. Os principais sintomas são náuseas, vômito, cãibras abdominais e diarreia. A febre costuma ser incomum nestes casos, mas quando presente normalmente está relacionada à ingestão de grandes quantidades da toxina (Santana et al., 2010).

\section{Conclusão}

A partir do exposto pode-se observar que as doenças transmitidas por alimentos são graves e comuns, entretanto ainda recebem pouco destaque. Os alimentos possuem um papel fundamental na economia de qualquer país e o investimento em políticas públicas voltadas à educação sanitária, produção de alimentos seguros e efetiva atuação dos sistemas de vigilância são alternativas úteis na divulgação, conscientização, prevenção e controle deste tipo de enfermidade que oferece sérios riscos e prejuízos à saúde pública.

\section{Referências bibliográficas}

Amson, G. V., Haracemiv, S. M. C., Masson, M. L. 2006. Levantamento de dados epidemiológicos relativos à ocorrências/surtos de doenças transmitidas por alimentos (DTAs) no Estado do Paraná - Brasil, no período de 1978 a 2000. Ciência e Agrotecnologia, 30 (6), 1139-1145.

Barreto, T. L. Sturion, G. L. 2010. Perfil epidemiológico dos surtos de toxinfecções alimentares em um município do Estado de São Paulo. Higiene Alimentari,24(180/181), 78-84. 
Berchieri Júnior, A., Silva, E. N., Di Fábio, J., Sesti, L. \& Zuanaze, M. A. F. 2015. Doenças das aves. Facta, Campinas.

BRASIL. Centro de Vigilância Epidemiológica. 2004. Manual de doenças transmitidas por alimentos.

BRASIL. Ministério da Saúde. 2010. Manual integrado de vigilância, prevenção e controle de doenças transmitidas por alimentos. 2. ed. Brasília.

BRASIL. Ministério da Saúde. 2011. Manual técnico de diagnóstico laboratorial da Salmonella spp. 1.ed. Brasília.

BRASIL. Ministério da Saúde. 2016. Surtos de doenças transmitidas por alimentos no Brasil. Brasília.

BRASIL. Ministério da Saúde. 2018. Surtos de doenças transmitidas por alimentos no Brasil. Brasília.

Caldorin, M., Almeida, I. A. Z. C., Peresi, J. T. M. \& Alves, E. C. A. 2013. Ocorrência de Escherichia coli produtora de toxina Shiga (STEC) no Brasil e sua importância em saúde pública. Boletim Epidemiológico Paulista, 10, 4-20.

Cangen, J. R. 2011. Food poisoning and diarrhea: Small intestine efectes. Curr Gastroenteral, 11, 442-448.

Cardoso, T. G. \& Carvalho, V. M. 2006. Toxinfecção alimentar por Salmonella spp. Revista do Instituto de Ciências da Saúde, 24, 95-101.

Cardoso, A. L. S. P. \& Tessari, E. N. C. Salmonella enteritidis em aves e na saúde pública: revisão de literatura. Revista Científica Eletrônica de Medicina Veterinária, 11, 1-27.

Dias, R. S., Leal-Bernardes, A. F. \& Zuccoli, P. C. 2011. A importância do processo de investigação na elucidação de surtos de Doenças Transmitidas por Alimentos (DTA). Periódico Científico do Núcleo de Biociências, 1, 17-23.

Feitosa, A. C., Rodrigues, R. M., Torres, E. A. T. \& Silva, J. F. M. 2017. Staphylococcus aureus em alimentos. Revista Desafios, 4, 1-17.

Ferraz, R. R. N., Santana, F. T., Barnabé, A. S. \& Fornari, J. V. 2015. Investigação de surtos de doenças transmitidas por alimentos como ferramenta de gestão em saúde de unidades de alimentação e nutrição. Revista de Administração e Ciências Contábeis do IDEAU, 9, 1-10.

Food Ingredients Brasil (FIB). 2011. Microorganismos causadores de doenças de origem alimentar. 19, 51-59.

Flores, A. M. P. C. \& Melo, C. B. 2015. Principais bactérias causadoras de doenças de origem alimentar. Revista Brasileira de Medicina Veterinária, 37, 65-72.

Forsythe, S. J. 2013. Microbiologia da segurança dos alimentos. Artmed, Porto Alegre.

Gabaron, D. A., Otutumi, L. K. \& Piau Júnior, R. 2015. Surtos de salmonelose notificados no período de janeiro de 2009 a julho de 2014 no estado do Paraná, Brasil. Arquivos de Ciências Veterinárias e Zoologia da UNIPAR, 18, 3337.

Germano, P. M. L. \& Germano, M. I. S. 2015. Higiene e vigilância epidemiológica de alimentos. Manole, Barueri.

Guilherme, D. L. \& Esteves, D. C. 2017. Doenças transmitidas por alimentos e água. Conexão Eletrônica, 14, 390-401.

Gyles, C. L. 2007. Shiga toxin-producing Escherichia coli: $\mathrm{Na}$ overview. Animal Science, 85, 45-62.

Karper, J. B., Nataro, J. P., Mobley, H. L. T. 2004. Pathogenic Escherichia coli. Nature Microbiology Reviews, 2, 123-140.

Klein, L. R., Bisognin, R. P. \& Figueiredo, D. M. S. 2017. Estudo do perfil epidemiológico dos surtos de doenças de transmissão hídrica e alimentar no Rio Grande do Sul: uma revisão dos registros do Estado. Revista Brasileira de Geografia Médica e da Saúde, 13, 48-64.

Lan, R., Alles, M. C., Donohoe, K., Martinez, M. B., Reeves, P. R. 2004. Molecular evolutionary relationships of enteroinvasive Escherichia coli and Shigella spp. Infection and Immunity, 72(9), 5080-5088.

Lopes, Antônio Carlos. 2006. Diagnóstico e tratamento. Manole, Barueri.

Luna, E. J. A. \& Silva Júnior, J. B. 2013. Doenças transmissíveis, endemias, epidemias e pandemias. Fundação Oswaldo Cruz, 3, 123176. 
Macedo, E. R., Fernandes, M. R., Amorim, M. A., Lima, T. L. \& de Carvalho, L. R. 2018. Epidemiological profile of acute diarrhea diseases notified in the municipal hospital of una-ba in the period from 2013 to 2014 Estácio Saúde, 7 (2), 25-30.

Machado, T. F. 2013. Patógenos emergentes em alimentos. Embrapa, Fortaleza.

Madigan, M. T., Martinko, J. M., Bender, K. S., Buckley, D. H. \& Stahl, D. A. 2016. Microbiologia de Broock. Artmed, Porto Alegre.

Malacrida, A. M., Dias, V. H. C. \& Lima, C. L. 2017. Perfil epidemiológico das doenças bacterianas transmitidas por alimentos no Brasil. II Simpósio de Produção Sustentável e Saúde Animal, Umuarama, Paraná.

Marchi, D. M., Baggio, N., Teo, C. R. P. A. \& Busato, M. A. 2011. Ocorrência de surtos de doenças transmitidas por alimentos no município de Chapecó, estado de Santa Cataria, Brasil, no período de 1995 a 2007. Epidemiologia e Serviços de Saúde, 20, 401407.

Marinho, G. A., Oliveira, G. S., Lima, J. L., Lopes, W. M. A., Nunes, G. A. \& Nunes, M. G. A. 2015. Perfil epidemiológico das doenças transmitidas por alimentos e seus fatores causais na região da zona da mata sul de Pernambuco. UNOPAR Científica: Ciências Biológicas e da Saúde, 17, 238-243.

Mittelstaedt, S. \& Carvalho, V. M. 2006. Escherichia coli enterohemorrágica (EHEC) O157:H7 - revisão. Revista do Instituto de Ciências da Saúde, 24, 175-182.

Morrow, W. E. M. \& Funk, J. Salmonella as a foodborne pathogen in pork. Animal Science Facts, 01 (816), 1-5.

Nunes, S. M., Cergole-Novella, M. C., Tiba, M. R., Zanon, C. A., Bento, I. S. S., Paschualinoto, A. L., Thomaz, I., Silva, A. A. \& Walendy, C. H. 2017. Surto de doença transmitida por alimentos nos municípios de Mauá e Ribeirão Pires - SP. Higiene Alimentar, 32, 97-102.

Oliveira, A. B. A., Paula, C. M. D., Capalonga, R., Cardoso, M. R. I. \& Tondo, E. C. 2010. Doenças transmitidas por alimentos, principais agentes etiológicos e aspectos gerais: uma revisão. HCPA, 30, 279-285.
Omoe, K., Hu, D. L., Takahashi-Omoe, H., Nakane, A., Shinagawa, K. 2005. Comprehensive analysis of classical and newly described staphylococcal superantigenic toxin genes in Staphylococcus aureus isolates. FEMS Microbiology Letters, 246 (2), 191-198.

Pinto, A. 1996. Doenças de origem microbiana transmitidas pelos alimentos. Millenium, 4:91100

Pizzolitto, N., Pizzolitto, E. L. \& Simões, M. J. S. 2007. Espectro de agentes etiológicos associados a surtos de doenças transmitidas por alimentos em núcleos receptores turísticos de três regiões geográficas do Estado de São Paulo. Revista de Ciências Farmacêuticas Básica e Aplicada, 28, 301-310.

Rodrigues, K. L., Moreira, A. N., Almeida, A. T. S., Chiochetta, D., Rodrigues, M. J., Brod, C. S., Carvalhal, J. B. \& Aleixo, J. A. G. 2004. Intoxicação estafilocócica em restaurante institucional. Ciência Rural, 34, 279-299.

Sales, L. M. \& Silva, T. M. 2012. Staphylococcus aureus meticilina resistente: um desafio para a saúde pública. Acta Biomedica Brasiliensa, 3, $1-13$.

Santana, E. H. W., Belotti, V., Aragon-Alegro, L. C. \& Mendonça, M. B. O. C. 2010. Estafilococos em alimentos. Arquivos do Instituto Biológico, 77, 545-554.

Scarcelli, E. \& Piatti, R. M. 2002. Patógenos emergentes relacionados à contaminação de alimentos de origem animal. Biológico, 64, 123-127.

Shinohara, N. K. S., Barros, V. B., Jimenez, S. M. C., Machado, E. C. L., Dutra, R. A. F. \& Lima Filho, J. L. 2008. Salmonella spp., importante agente patogênico veiculado em alimentos. Ciência e Saúde Coletiva, 13, 1-9.

Silva, E. P., Bergamini, A. M. M. \& Oliveira, M. A. 2010. Alimentos e agentes etiológicos envolvidos em toxinfecções na região de Ribeirão Preto, SP, Brasil - 2005 a 2008. Boletim Epidemiológico Paulista, 77, 1-6.

Silva, J. C. G., Silva Filho, M. M., Nascimento, G. V., Pereira, D. A. B. \& Costa Júnior, C. E. O. 2017. Incidência de doenças transmitidas por alimentos (DTA) no estado de Pernambuco, um acompanhamento dos dados epidemiológicos nos últimos anos. Ciências Biológicas e de Saúde UNIT, 3, 23-34. 
Silva, Y. 2009. Doenças transmitidas por alimentos no município do Rio de Janeiro: perfil epidemiológico e controle. Instituto Nacional de Controle de Qualidade em Saúde, Fundação Oswaldo Cruz, Rio de Janeiro, Rio de Janeiro.

Sirtoli, D. B. \& Camarella, L. 2018. O papel da vigilância sanitária na prevenção das doenças transmitidas por alimentos (DTA). Saúde $e$ Desenvolvimento, 12, 197-209.

Teixeira, A. F. M. 2010. Doenças microbianas de origem alimentar. Academia de Ciência e Tecnologia, 3, 1-8.

Tharuk, M., Olafsson, S., Lee, J. S., Hurburg, C. R. 2010. Data mining for recognizing patterns in foodborne disease outbreaks. Journal of Food Engineering, 97, 213-227.
Welker, C. A. D., Both, J. M. C., Longaray, S. M., Haas, S., Soeiro, M. L. T. \& Ramos, R. C. 2010. Análise microbiológica dos alimentos envolvidos em surtos de doenças transmitidas por alimentos (DTA) ocorridos no estado do Rio Grande do Sul, Brasil. Revista Brasileira de Biociências, 8, 44-48.

Recebido: 28 Agosto, 2018

Aprovado: 24 Setembro, 2018

Publicado: 19 Outubro 2018

Licenciamento: Este artigo é publicado na modalidade Acesso Aberto sob a licença Creative Commons Atribuição 4.0 (CC-BY 4.0), a qual permite uso irrestrito, distribuição, reprodução em qualquer meio, desde que o autor e a fonte sejam devidamente creditados. 